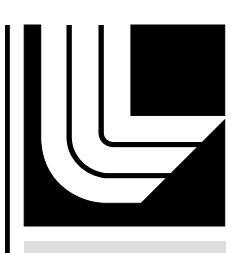

LAWRENCE LIVERM ORE NATIONAL LABORATORY

Diagnostic options for radiative divertor feedback control on NSTX-U

V. A. Soukhanovskii, S. P. Gerhardt, R. Kaita, A. G. McLean, R. Raman

May 8, 2012

Review of Scientific Instruments 
This document was prepared as an account of work sponsored by an agency of the United States government. Neither the United States government nor Lawrence Livermore National Security, LLC, nor any of their employees makes any warranty, expressed or implied, or assumes any legal liability or responsibility for the accuracy, completeness, or usefulness of any information, apparatus, product, or process disclosed, or represents that its use would not infringe privately owned rights. Reference herein to any specific commercial product, process, or service by trade name, trademark, manufacturer, or otherwise does not necessarily constitute or imply its endorsement, recommendation, or favoring by the United States government or Lawrence Livermore National Security, LLC. The views and opinions of authors expressed herein do not necessarily state or reflect those of the United States government or Lawrence Livermore National Security, LLC, and shall not be used for advertising or product endorsement purposes. 


\title{
Diagnostic options for radiative divertor feedback control on NSTX-U. ${ }^{a)}$
}

\author{
V. A. Soukhanovskii, ${ }^{1,}$ b) S. P. Gerhardt, ${ }^{2}$ R. Kaita, ${ }^{2}$ A. G. McLean, ${ }^{1}$ and R. Raman ${ }^{3}$ \\ ${ }^{1)}$ Lawrence Livermore National Laboratory, Livermore, California, 94550 \\ 2) Princeton Plasma Physics Laboratory, Princeton, New Jersey 08540 \\ 3) University of Washington, Seattle, Washington 98195
}

A radiative divertor technique is used in tokamak experiments and planned for ITER to mitigate high heat loads on divertor plasma-facing components (PFCs) to prevent excessive material erosion and thermal damage. Impurity (or hydrogenic) gas seeding is employed to induce volumetric power and momentum losses in the divertor plasma that reduce heat and particle fluxes on divertor target plates. In the National Spherical Torus Experiment (NSTX), a large spherical tokamak with lithium-coated graphite PFCs and high divertor heat flux $\left(q_{\text {peak }} \leq 15 \mathrm{MW} / \mathrm{m}^{2}\right)$, radiative divertor experiments employed pre-programmed $\mathrm{D}_{2}$ or $\mathrm{CD}_{4}$ gas injections, and demonstrated a significant reduction of divertor peak heat flux simultaneously with good core $\mathrm{H}$-mode confinement. In the NSTX-U device, steady-state peak divertor heat fluxes are projected to reach 20-30 MW $/ \mathrm{m}^{2}$. In this work diagnostic options available on NSTX-U for development and characterization of real-time feedback control of divertor heat flux are discussed. A digital plasma control system would employ a signal from one of the divertor and pedestal diagnostics to control the divertor detachment process via an actuator (impurity gas seeding rate).

\section{INTRODUCTION}

A radiative (partially detached) divertor technique is used in tokamak experiments and planned for ITER to mitigate high divertor heat loads and material erosion of divertor plasma-facing components (PFCs) to prevent their thermal and structural damage ${ }^{1,2}$. The radiative divertor uses induced divertor volumetric power and momentum losses to reduce heat and particle fluxes on divertor target plates. Deuterium and/or impurity gas seeding has been employed to control the radiative divertor plasma parameters in several tokamak experiments via a real-time feedback control of the gas injection rate $^{3-8}$. Whereas a full predictive understanding of divertor detachment physics is still lacking ${ }^{2}$, the scrape-off layer (SOL) plasma transport and atomic physics elements are sufficiently understood for control purposes. The goal is to measure and interpret the onset, spatial extent and plasma parameters of the divertor strike point detachment region, and sustain it for many plasma confinement times (ideally in steady-state) without significantly affecting pedestal temperature and core confinement.

In the National Spherical Torus Experiment (NSTX), a large spherical tokamak with lithium-coated graphite PFCs and high divertor heat flux $\left(q_{\text {peak }} \leq 15 \mathrm{MW} / \mathrm{m}^{2}\right.$, $q_{\|} \leq 200 \mathrm{MW} / \mathrm{m}^{2}$ (Ref. $\left.^{9}\right)$ ), radiative divertor experiments employed $\mathrm{D}_{2}, \mathrm{CD}_{4}$, or $\mathrm{Ne}$ gas injections that were controlled by pre-programmed waveforms ${ }^{10-13}$. In this work we discuss the diagnostic development plan in preparation for real-time feedback control of divertor conditions in the NSTX Upgrade facility. At present, the NSTX facility is being upgraded to new capabilities that

\footnotetext{
a) Contributed paper P.6.18 published as part of the Proceedings of the 19th Topical Conference on High-Temperature Plasma Diagnostics, Monterey, California, May, 2012.

b) Electronic mail: vlad@llnl.gov
}

are expected to extend physics studies of the spherical tokamak (ST) to advance the ST as a candidate for the Fusion Nuclear Science Facility. In the NSTX-U device ${ }^{14}$, discharges with $I_{p} \leq 2 \mathrm{MA}$ and $P_{N B I} \leq 12.3 \mathrm{MW}$ and up to $5 \mathrm{~s}$ duration are projected to produce steady-state peak divertor heat fluxes in the range $20-30 \mathrm{MW} / \mathrm{m}^{2}$, thereby challenging thermal limits of divertor $\mathrm{PFCs}^{9}$. The leading heat flux mitigation candidates for NSTX-U are considered to be the snowflake divertor geometry ${ }^{15,16}$ and the impurity-seeded radiative technique applied to the lower and upper divertors.

\section{CONCEPTUAL DESIGN OF REAL-TIME RADIATIVE DIVERTOR FEEDBACK CONTROL SYSTEM}

The divertor detachment process is tokamak-specific with respect to divertor $\mathrm{PFC}$ material, seeding gas species, radiating impurity, onset parameters and their relation to the core plasma. The radiative detachment of the divertor SOL is achieved when heat conduction can no longer be sustained as a result of high SOL collisionality and high volumetric power and momentum losses. The detachment signatures universally measured in present-day tokamak experiments include 1) the loss of plasma pressure $T_{e} n_{e}$ along the SOL (field line) from upstream locations to the target, increased divertor $n_{e} \leq 10^{15} \mathrm{~m}^{-3}$ and decreased $\left.T_{e} \leq 1-2 \mathrm{eV} ; 2\right)$ the reduction of divertor heat flux (esp. $q_{\text {peak }}$ ) and increase in $P_{r a d}$; and 3 ) reduction of ion flux density to the plate, accompanied by an increased volumetric recombination rate $\mathrm{e}^{1,2}$. In order to control radiative detachment, a diagnostic control signal must be unambiguously linked to the divertor state. The feedback control signals that have been used in tokamak experiments include the radiated power or spectroscopic surrogates for the radiated power $^{3,5,17,18}$, direct $T_{e}$ or $n_{e}$ measurements ${ }^{4,19}$, or a surrogate for the $T_{e}$ measurement ${ }^{8}$. The temporal evolution of detachment characteristics occur on the scale of tens 
to hundreds of ms. Fast transient phenomena, e.g. ELMs or MHD events that may affect the control signal, must be detected and filtered out numerically ${ }^{8}$.

The digital plasma control system (PCS) implemented in NSTX $^{20}$ used a special computer that interpreted realtime control signals and acted on the system (plasma) via an actuator to change the system toward reference conditions. It is envisioned that the divertor feedback control can be accomplished using a commonly used proportional, integral, derivative (PID) controller algorithm in the PCS. The control signal $S_{c}$ is measured in real time and compared to the reference signal $S_{r e f}: \Delta S=$ $S_{c}-S_{\text {ref }}$. The actuator signal $V$ is calculated in real-time according to: $V=K_{0}+K_{p} \Delta S+K_{i} \int_{t_{1}}^{t_{2}} \Delta S d t+K_{d} d \Delta S / d t$ where $K_{i}$ are the proportional, integral, derivative control gains that are usually estimated or modeled off-line and verified in the experiment. If a calibrated valve that controls impurity seeding is the actuator, then the actuator $V$ is a real-time voltage proportional to a gas flow rate. In this regard, the system is quite similar to many quantities, e.g. divertor strike point positions, controlled via PID-based algorithms in NSTX PCS ${ }^{21}$.

In previous NSTX experiments, a single-channel divertor gas injector was used (a similar system described in Ref. ${ }^{22}$ ). The system was comprised of piezoelectec valves (Veeco PV-10 or Maxtec Inc. MV-112 with a response time of several ms and control voltage up to 150 V), and operated at pressures up to 100 PSIG $(\sim 5000$ Torr). For NSTX-U, an upgrade to the system is proposed. The upgraded system would include four outlets placed axi-symmetrically in the lower and upper divertor regions in the physical gaps between divertor plates. However, the valves would still be about 1.5-2 m from the outlets, resulting in a characteristic system time of about $100 \mathrm{~ms}$. (required for the room-temperature gas to propagate in a viscous flow regime at a sound speed through a pipe). To control the gas inventory, existing turbo-molecular pumps and a divertor cryogenic panel (which is presently under consideration), would be used.

The seeding impurity gas is selected based on operational and atomic physics (radiated power at low $T_{e}$ ) considerations. It is envisioned that all graphite PFCs, conditioned via lithium and boron coatings, would be used in the initial period of NSTX-U operations ${ }^{14}$. Substantial operational experience with graphite PFCs and $\mathrm{D}_{2}, \mathrm{CD}_{4}$, and Ar seeding exists. Nitrogen is excluded at this stage, as it reacts chemically with lithium coatings resulting in a stable nitrate compound; nitrogen also tends to be adsorbed into graphite. However, if NSTXU PFCs are eventually upgraded to molybdenum and/or tungsten, $\mathrm{D}_{2}, \mathrm{~N}_{2}$ and Ar would be used.

\section{DIAGNOSTIC OPTIONS FOR NSTX-U}

It is expected that the same diagnostics used in NSTX $^{12,13}$ would be available for NSTX-U divertor characterization during initial operations. A significant re-

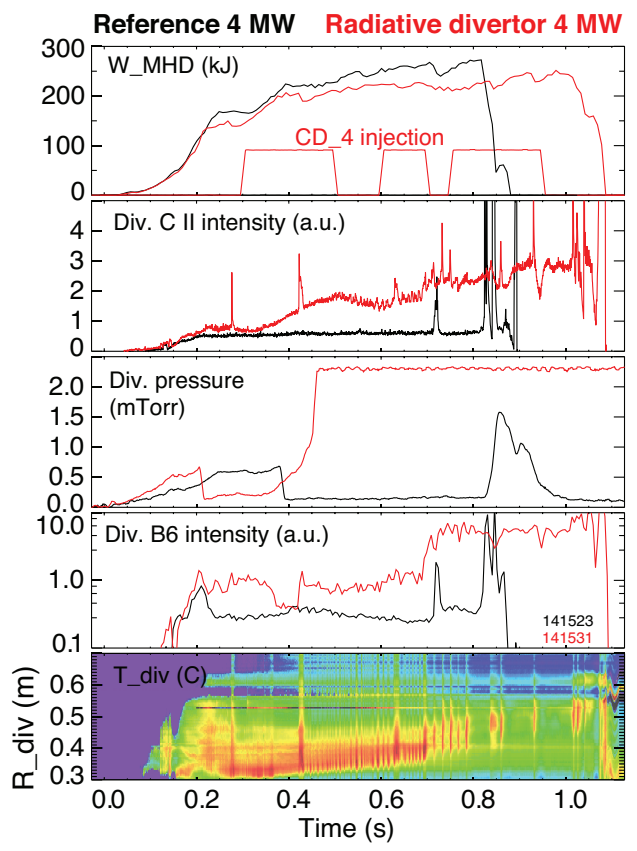

FIG. 1. Time traces of a reference (black) and a radiative divertor (red) H-mode discharges: (a) Plasma stored energy $W_{M H D}$ and $\mathrm{CD}_{4}$ injection waveforms, (b) divertor C II $(\lambda 658.5 \mathrm{~nm})$ intensity, (c) divertor neutral pressure, (d) divertor Balmer $n=2-6$ line intensity in the strike point region, (e) divertor PFC temperature from IR thermography.

duction of divertor heat flux, from peak values of 4$10 \mathrm{MW} / \mathrm{m}^{2}$ to $0.5-2 \mathrm{MW} / \mathrm{m}^{2}$, simultaneously with good core $\mathrm{H}$-mode confinement characterized by $\mathrm{H} 98(\mathrm{y}, 2)$ up to 1 , has been demonstrated in 1.0-1.3 s discharges ${ }^{10-13}$. Based on these experiments, we identify two categories of diagnostics that can be used as control signals on NSTXU. These include 1) divertor plasma and PFC diagnostics; and 2) the diagnostics characterizing the pedestal or core plasma that can be used as "security" measures insuring compatibility of the fedback radiative divertor with H-mode confinement. A partial divertor strike point detachment was characterized in NSTX using a number of divertor plasma measurements: divertor plate temperature (heat flux), radiated power with bolometry and impurity radiation with spectroscopy, neutral gas pressure measurements, ion flux with Langmuir probes, and divertor recombination with spectroscopy. Shown in Fig. 1 are divertor time traces in two 0.8 MA 4 MW NBI-heated $\mathrm{H}$-mode discharges, a reference discharge and a radiative divertor discharge with $\mathrm{CD}_{4}$ seeding. In the radiative divertor discharge, peak divertor heat flux was reduced from 4-5 to 1-2 $\mathrm{MW} / \mathrm{m}^{2}$ in the detachment phase that started at about $0.7 \mathrm{~s}$. These time traces will be used to illustrate control signal options for NSTX-U.

Initial considerations for spatial and temporal requirements to the control signal are as follows. The characteristic detachment onset time in NSTX was on the order of ten ms, and is not expected to be different in NSTX-U. 
If the detachment spatial extent is important, the control signal spatial resolution should be about $1 \mathrm{~cm}$. The ability to distinguish between inner and outer divertor leg parameters is also important. Typically, up to $50 \%$ of the SOL power width $\lambda_{q}$ (up to $10 \mathrm{~cm}$ in the divertor) was affected by radiative detachment in $\mathrm{NSTX}^{12,13}$. As $\lambda_{q}$ is projected to be reduced in NSTX- ${ }^{9}$, the detachment region (including the flux expansion factor), would probably be reduced to several $\mathrm{cm}$.

Radiated power A signal representing spectrally integrated radiation as well as spectrally resolved impurity emission can be used to monitor divertor radiated power. In NSTX, bolometer signals showed a 50-75 \% increase during detachment ${ }^{12}$, as would impurity spectroscopy, as shown in Fig. 1. A number of spectroscopic options are available for NSTX-U. A major fraction of the power radiated by $\mathrm{C}, \mathrm{N}$, or Ar impurities at typical divertor conditions is in the $8-30 \mathrm{eV}$ photon energy range. A divertor radiometer based on a single AXUV diode or an AXUV array (similar to the previously implemented on $\mathrm{NSTX}^{23}$ ) could be used. The AXUV diodes are widely used for plasma bolometry (despite the non-uniformity of the AXUV diode spectral response). Another option is impurity vacuum ultraviolet (VUV) line emission spectroscopy ${ }^{24}$, e.g., a dedicated VUV monochromator aimed at certain strong impurity emission lines as discussed in $\operatorname{Re}^{24,25}$, or a survey VUV spectrometer.

Neutral pressure A divertor Penning gauge ${ }^{26}$ showed an order of magnitude increase (or even saturation, Fig. 1) in neutral pressure during gas-induced detachment $^{13}$, suggesting that seeded impurity pressure measurements could be used in NSTX-U for radiative divertor feedback control as well. Another option under development for NSTX-U is a spectroscopically-monitored Penning gauge ${ }^{27}$ calibrated for impurity gas pressure measurements in the range 0.1-5 mTorr.

Electron-ion recombination Divertor observations in NSTX $^{12,28-30}$ showed that hydrogenic Balmer or Paschen series emission lines are good indicators of volumetric recombination taking place during the detachment (Fig. 1) and a very sensitive diagnostic of divertor $T_{e} \leq 1-2$ $\mathrm{eV}$ and $n_{e} \geq 5 \times 10^{19} \mathrm{~m}^{-3}$. Intensity of the high- $n$ series lines is proportional to the volumetric recombination rate $^{31}$, and can increas by 1-2 orders of magnitude during detachment ${ }^{13}$. A dedicated filtered spectroscopic detector or an imaging UV spectrometer (as implemented in $\mathrm{NSTX}^{23}$ ) could be used.

Surface temperature In NSTX, PFC temperature and divertor heat fluxes were routinely monitored using infrared (IR) thermography ${ }^{32}$ and slow thermocouples. Divertor PFC temperature in the strike point region was reduced from 600-1000 to 150-250 deg. C during detachment (Fig. 1). A simple robust solution for NSTX$\mathrm{U}$ could thus include medium $(3-5 \mu \mathrm{m})$ and/or longwavelength $(5-15 \mu \mathrm{m})$ IR thermography: dedicated oneor two-dimensional IR arrays, or even a single-channel IR diode with views averaging over the strike point region.
Thermoelectric SOL current Another attractive option for NSTX-U is a real-time thermoelectric SOL current measurement. Due to thermoelectric effects, i.e. because of the $T_{e}$ difference between inner and outer (or upper and lower) divertors, currents can flow in the $\mathrm{SOL}^{33}$. The measured current can be related to divertor $T_{e}$ and used for radiative divertor control ${ }^{8,34}$. In NSTX, the inner and outer parts of the vacuum vessel (and PFCs) were electrically isolated to enable non-inductive plasma start-up via coaxial helicity injection $(\mathrm{CHI})^{35}$. In CHI experiments, the outer vessel (divertor) was connected to the ground, whereas the inner vessel (divertor) was floating. The electric potential $V_{i o}$ between inner and outer strike point regions was monitored. This is illustrated in Fig. 2 where time traces of two CHI discharges are shown. The black traces illustrate a discharge with CHI start-up that eventually went into an $\mathrm{H}$-mode at about $0.17 \mathrm{~s}$, with a steady-state $V_{i o} \simeq 300$ volts $^{35}$. The red traces illustrate a steady-state inductive discharge, with CHI voltage applied at about $0.450 \mathrm{~s}$. At that time $V_{i o}$ reached about $250 \mathrm{~V}$ and the application of the CHI reduced $V_{i o}$ to nearly zero. In NSTX-U, electrical insulation between the inner and outer vessel will be improved. Further development of this capability aimed at better understanding of SOL thermoelectric currents, as well as active biasing experiments, are planned for NSTX-U.

One concern with spatially (both poloidally and toroidally) localized divertor signals is that they can be affected by changes in plasma shaping, strike-point lo-

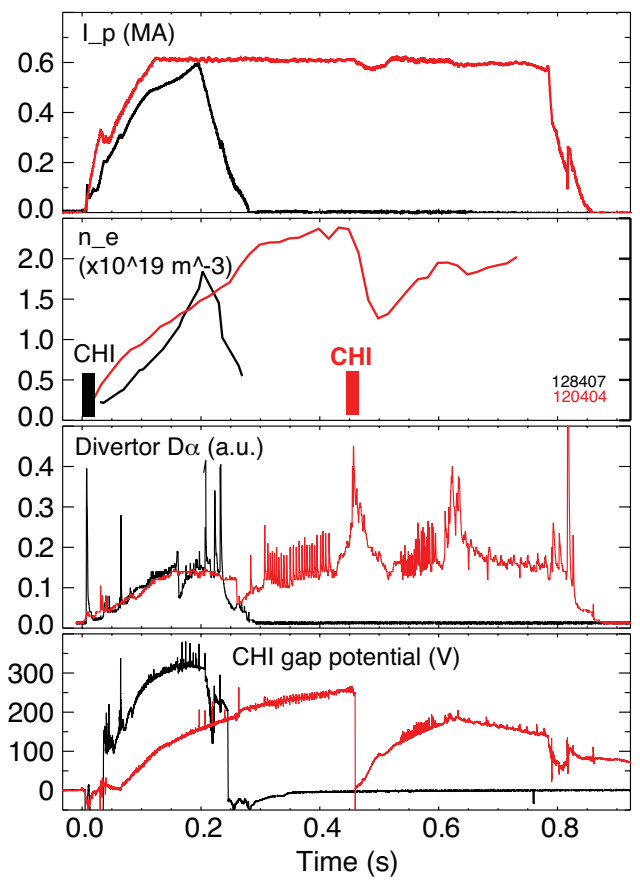

FIG. 2. Time traces of (a) $I_{p}$, (b) $n_{e}$, (c) divertor $\mathrm{D}_{\alpha}$ intensity, (d) $V_{i o}$ in $\mathrm{CHI} \mathrm{H}$-mode discharge (black traces) and an inductive discharge with CHI current applied at $0.450 \mathrm{~s}$ (black traces). 
cations, and toroidal asymmetries in heat and particle fluxes during the application of 3D fields. This could limit the operating space of the control system if it is based on a single spatially localized diagnostic such as a Langmuir probe, a thermocouple, or toroidally localized IR or spectroscopic measurement. Some signals, e.g., the radiated power, spectroscopic impurity and recombination, and gas pressure measurements represent toroidally-averaged quantities and avoid the spatial localization problem.

Integration with core plasma Unchanged core H-mode confinement with high-pressure pedestal is one of the goals of real-time radiative divertor control. Reduced pedestal temperature and X-point MARFE formation are main concerns if too much impurity gas is requested by the PCS for divertor heat flux mitigation. Signals that reflect these parameters can provide "security" monitoring (as in e.g. Ref., ${ }^{49}$ ) and will be needed in long-pulse NSTX-U discharges utilizing the radiative divertor. The implementation of these security signals would involve multi-variate controllers in PCS. A number of NSTX diagnostics can provide these security signals. Signals from existing soft X-ray arrays were related to edge $T_{e}$ via an impurity radiation and transport model and calibrated using multi-point Thomson scattering measurements ${ }^{36,37}$. Pedestal temperature in the range $100-500 \mathrm{eV}$ can be monitored. If an X-point MARFE develops in the divertor region during excessive gas puffing, divertor recombination monitors described above can be used. Finally, a real-time Thomson scattering diagnostic can be used for $T_{e}$ monitoring in the H-mode pedestal region.

In conclusion, we reviewed a number of diagnostic options available for implementation and testing as radiative divertor feedback control signals in the initial NSTXU operation period. Further work will focus on developing and testing diagnostic prototypes, developing timedependent models of the control diagnostic performance, and implementing the control algorithms in the PCS.

Acknowledgments Entire NSTX Team is acknowledged for research, plasma, and neutral beam operations. This work was performed under the auspices of the U.S. Department of Energy under Contracts DEAC52-07NA27344, DE-AC02-09CH11466 and DE-AC0500OR22725.

\footnotetext{
${ }^{1}$ ITER Physics Expert Group on Divertor, ITER Physics Expert Group on Divertor Modelling, and Database and ITER Physics Basis Editors, Nucl. Fusion 39, 2391 (1999).

${ }^{2}$ A. Loarte, B. Lipschultz, A. Kukushkin, G. Matthews, P. Stangeby, N. Asakura, G. Counsell, G. Federici, A. Kallenbach, K. Krieger, A. Mahdavi, V. Philipps, D. Reiter, J. Roth, J. Strachan, D. Whyte, R. Doerner, T. Eich, W. Fundamenski, A. Herrmann, M. Fenstermacher, P. Ghendrih, M. Groth, A. Kirschner, S. Konoshima, B. LaBombard, P. Lang, A. Leonard, P. Monier-Garbet, R. Neu, H. Pacher, B. Pegourie, R. Pitts, S. Takamura, J. Terry, E. Tsitrone, and the ITPA DSOL Physics Topical Group, Nucl. Fusion 47, S203 (2007).

${ }^{3}$ G. Jackson, G. Staebler, S. Allen, N. Brooks, T. Evans, J. Ferron, A. Leonard, R. Maingi, T. Petrie, M. Schaffer, R. Wood, W. West, and D. Whyte, J. Nucl. Mater. 241-243, 618 (1997).
}

${ }^{4}$ J. Bucalossi, J. Gunn, A. Geraud, P. Ghendrih, C. Grisolia, A. Grosman, G. Martin, D. Moulin, J.-Y. Pascal, and F. SaintLaurent, J. Nucl. Mater. 290-293, 566 (2001).

${ }^{5}$ H. Tamai, S. Konoshima, N. Hosogane, N. Asakura, S. Sakata, N. Saito, K. Akiba, H. Akasaka, Y. Kawamata, and K. Kurihara, Fusion Eng. Des. 39-40, 163 (1998).

${ }^{6}$ H. Tamai, N. Asakura, N. Hosogane, H. Takenaga, S. Higashijima, K. Itami, S. Konoshima, H. Kubo, A. Sakasai, S. Sakurai, and K. Shimizu, J. Nucl. Mater. 266-269, 1219 (1999).

${ }^{7}$ B. Lipschultz, J. Goetz, B. LaBombard, G. McCracken, H. Ohkawa, Y. Takase, and J. Terry, J. Nucl. Mater. 241-243, 771 (1997).

${ }^{8}$ A. Kallenbach, R. Dux, J. Fuchs, R. Fischer, B. Geiger, L. Giannone, A. Herrmann, T. Lunt, V. Mertens, R. McDermott, R. Neu, T. Putterich, S. Rathgeber, V. Rohde, K. Schmid, J. Schweinzer, and W. Treutterer, Plasma Phys. Control. Fusion 52, 055002 (2010).

${ }^{9}$ T. Gray, R. Maingi, V. Soukhanovskii, J. Surany, J.-W. Ahn, and A. McLean, J. Nucl. Mater. 415, S360 (2011).

${ }^{10}$ V. Soukhanovskii, R. Maingi, A. Roquemore, J. Boedo, C. Bush, R. Kaita, H. Kugel, B. LeBlanc, S. Paul, G. Porter, and N. Wolf, J. Nucl. Mater. 337-339, 475 (2005).

${ }^{11}$ V. Soukhanovskii, R. Maingi, C. Bush, R. Raman, R. Bell, R. Kaita, H. Kugel, C. Lasnier, B. LeBlanc, J. Menard, S. Paul, A. Roquemore, and T. Team, J. Nucl. Mater. 363-365, 432 (2007).

${ }^{12}$ V. Soukhanovskii, R. Maingi, D. Gates, J. Menard, S. Paul, R. Raman, A. Roquemore, M. Bell, R. Bell, J. Boedo, C. Bush, R. Kaita, H. Kugel, B. LeBlanc, and D. Mueller, Phys. Plasmas 16, 022501 (2009).

${ }^{13}$ V. Soukhanovskii, R. Maingi, D. Gates, J. Menard, S. Paul, R. Raman, A. Roquemore, R. Bell, C. Bush, R. Kaita, H. Kugel, B. LeBlanc, and D. Mueller, Nucl. Fusion 49, 095025 (2009).

${ }^{14}$ J. Menard, J. Canik, J. Chrzanowski, M. Denault, L. Dudek, S. Gerhardt, S. Kaye, C. Kessel, E. Kolemen, R. Maingi, C. Neumeyer, M. Ono, E. Perry, R. Raman, S. Sabbagh, M. Smith, V. Soukhanovskii, T. Stevenson, R. Strykowsky, P. Titus, K. Tresemer, M. Viola, and M. Williams, "Overview of the physics and engineering design of NSTX Upgrade," Proceedings of the 24th IEEE Symposium on Fusion Engineering (2011).

${ }^{15}$ D. Ryutov, Phys. Plasmas 14, 64502 (2007).

${ }^{16}$ V. Soukhanovskii, J.-W. Ahn, R. Bell, D. Gates, S. Gerhardt, R. Kaita, E. Kolemen, B. LeBlanc, R. Maingi, M. Makowski, R. Maqueda, A. McLean, J. Menard, D. Mueller, S. Paul, R. Raman, A. Roquemore, D. Ryutov, S. Sabbagh, and H. Scott, Nucl. Fusion 51, 012001 (2011)

${ }^{17}$ A. Kallenbach, R. Dux, V. Mertens, O. Gruber, G. Haas, M. Kaufmann, W. Poschenrieder, F. Ryter, H. Zohm, M. Alexander, K. Behringer, M. Bessenrodt-Weberpals, H.-S. Bosch, K. Buchl, A. Field, J. Fuchs, O. Gehre, A. Herrmann, S. Hirsch, W. Koppendorfer, K. Lackner, K. Mast, G. Neu, J. Neuhauser, S. D. P. Hempel, G. Raupp, K. Schonmann, A. Stabler, K.-H. Steuer, O. Vollmer, M. Weinlich, W. West, and T. Zehetbauer, Nucl. Fusion 35, 1231 (1995).

${ }^{18}$ J. A. Goetz, B. LaBombard, B. Lipschultz, C. S. Pitcher, J. L. Terry, C. Boswell, S. Gangadhara, D. Pappas, J. Weaver, B. Welch, R. L. Boivin, P. Bonoli, C. Fiore, R. Granetz, M. Greenwald, A. Hubbard, I. Hutchinson, J. Irby, E. Marmar, D. Mossessian, M. Porkolab, J. Rice, W. L. Rowan, G. Schilling, J. Snipes, Y. Takase, S. Wolfe, and S. Wukitch, Phys. Plasmas 6, 1899 (1999).

${ }^{19}$ J. Gunn, J. Bucalossi, L. Costanzo, C. Grisolia, P. Ghendrih, A. Grosman, T. Loarer, G. Martin, P. Monier-Garbet, D. Moulin, J.-Y. Pascal, and F. Saint-Laurent, Plasma Phys. Control. Fusion 42, 557 (2000).

${ }^{20}$ D. Gates, J. Ferron, M. Bell, T. Gibney, R. Johnson, R. Marsala, D. Mastrovito, J. Menard, D. Mueller, C. Neumeyer, B. Penaflor, and T. Stevenson, Fusion Eng. Des. 81, 1911 (2006).

${ }^{21}$ E. Kolemen, D. Gates, C. Rowley, N. Kasdin, J. Kallman, S. Gerhardt, V. Soukhanovskii, and D. Mueller, Nucl. Fusion 50, 
105010 (2010).

${ }^{22}$ V. Soukhanovskii, M. Bell, W. Blanchard, J. Dong, R. Gernhardt, R. Kaita, H. Kugel, T. Provost, A. Roquemore, and P. Sichta, "High-pressure supersonic gas jet fueling on NSTX," Procedings of the 22nd IEEE/NPSS Symposium on Fusion Engineering , 178 (2007).

${ }^{23}$ V. Soukhanovskii, A. Roquemore, R. Bell, R. Kaita, and H. Kugel, Rev. Sci. Instrum. 81, 10723 (2010).

${ }^{24}$ V. Soukhanovskii, D. Stutman, M. May, M. Finkenthal, H. Moos, J. Terry, J. Goetz, and B. Lipschultz, Rev. Sci. Instrum. 70, 340 (1999).

${ }^{25}$ V. Soukhanovskii, D. Stutman, M. Finkenthal, H. Moos, R. Kaita, and R. Majeski, Rev. Sci. Instrum. 72, 3270 (2001).

${ }^{26}$ R. Raman, H. W. Kugel, R. Gernhardt, T. Provost, T. R. Jarboe, and V. Soukhanovskii, Rev. Sci. Instrum. 75, 4347 (2004).

${ }^{27}$ K. Finken, K. Dippel, W. Baek, and A. Hardtke, Rev. Sci. Instrum. 63, 1 (1992).

${ }^{28}$ V. Soukhanovskii, J. Ahn, R. Bell, D. Gates, S. Gerhardt, R. Kaita, E. Kolemen, H. Kugel, B. LeBlanc, R. Maingi, R. Maqueda, A. McLean, J. Menard, D. Mueller, S. Paul, R. Raman, A. Roquemore, D. Ryutov, and H. Scott, J. Nucl. Mater. 415, S365 (2011).

${ }^{29}$ V. Soukhanovskii, D. Johnson, R. Kaita, and A. Roquemore, Rev. Sci. Instrum. 77, 10127 (2006).
${ }^{30}$ V. Soukhanovskii, Rev. Sci. Instrum. 79, 10539 (2008).

${ }^{31}$ J. Terry, B. Lipschultz, X. Bonnin, C. Boswell, S. Krasheninnikov, A. Pigarov, B. LaBombard, D. Pappas, and H. Scott, J. Nucl. Mater. 266-269, 30 (1999).

32 J.-W. Ahn, R. Maingi, D. Mastrovito, and A. Roquemore, Rev. Sci. Instrum. 81, 023501 (2010).

${ }^{33}$ G. Staebler and F. Hinton, Nucl. Fusion 29, 1820 (1989).

${ }^{34}$ A. Kallenbach, A. Carlson, G. Pautasso, A. Peeters, U. Seidel, and H.-P. Zehrfeld, J. Nucl. Mater. 290-293, 639 (2001).

${ }^{35}$ R. Raman, T. Jarboe, D. Mueller, B. Nelson, M. Bell, R. Bell, D. Gates, S. Gerhardt, J. Hosea, R. Kaita, H. Kugel, B. LeBlanc, R. Maingi, R. Maqueda, J. Menard, M. Nagata, M. Ono, S. Paul, L. Roquemore, S. Sabbagh, V. Soukhanovskii, and G. Taylor, Nucl. Fusion 49, 065006 (2009).

${ }^{36}$ L. F. Delgado-Aparicio, D. Stutman, K. Tritz, M. Finkenthal, R. Bell, J. Hosea, R. Kaita, B. LeBlanc, L. Roquemore, and J. R. Wilson, J. App. Phys. 102, 073304 (2007).

${ }^{37}$ K. Tritz, D. Stutman, L. Delgado-Aparicio, M. Finkenthal, R. Kaita, and L. Roquemore, Rev. Sci. Instrum. 81, 10502 (2010). 